\title{
Kebiasaan Makanan Ikan Gelodok (Periophthalmus sp.) di Kawasan Mangrove Pantai Meras, Kecamatan Bunaken, Kota Manado, Sulawesi Utara (The Food Habit of Mudskipper Fish, Periophthalmus sp. in Mangrove Areas of Meras Beach, Bunaken District, Manado City, North Sulawesi)
}

\author{
Lidyana Maya Gosal' ${ }^{1)}$,Deidy Yulius Katili(2), Marina F O Singkoh ${ }^{2)}$, Jan EWS Tamanampo ${ }^{3)}$ \\ 1)Alumni Jurusan Biologi Fakultas MIPA Universitas Sam Ratulangi Manado \\ 2) Jurusan Biologi Fakultas MIPA Universitas Sam Ratulangi Manado \\ 3) Jurusan Manajemen Sumberdaya Perikanan Fakultas Perikanan dan Kelautan Manado \\ *Email korespondensi: lidya_gosal@yahoo.com
}

Diterima 25 Juli 2013, diterima untuk dipublikasikan 5 Agustus 2013

\begin{abstract}
Abstrak
Telah dilakukan penelitian untuk mengamati kebiasaan makanan ikan gelodok di kawasan mangrove Pantai Meras, Kecamatan Bunaken, Kota Manado, Sulawesi Utara. Kebiasaan makanan ikan gelodok menyangkut jenis-jenis makanan, persentase nilai dari suatu jenis makanan dan nilai bagian terbesar dari komposisi makanannya. Metode yang digunakan di lapangan adalah metode random sampling dengan 30 individu ikan sebagai sampel. Identifikasi jenis-jenis makanan ikan menggunakan mikroskop dengan pembesaran 100x. Hasil analisis dengan menggunakan Indeks Bagian Terbesar didapatkan bahwa makanan utama adalah Crustacea, makanan pelengkap adalah zooplankton, fitoplankton, Polychaeta dan makanan tambahan adalah Hexapoda.

Kata kunci : Ikan gelodok, kebiasaan makanan
\end{abstract}

\section{Abstract}

A study to observe the food habit of mudskipper fish in mangrove areas of Meras Beach, Bunaken District, Manado City, and North Sulawesi was conducted. This feeding manner included food types, the percentage value of a particular food and the largest value of food composition. The random sampling method using 30 fish was applied in the site location. The food type of this fish was identified using a microscope with 100x magnification. Results of this research showed that the main food was crustacean, the complementary food was zooplankton, phytoplankton, Polychaeta, and the supplementary food was Hexapoda.

Keywords : mudskipper fish, food habits

\section{PENDAHULUAN}

Ikan gelodok termasuk dalam

Family Gobiidae dan Subfamily Oxudercinae. Ikan gelodok merupakan salah satu jenis ikan yang memiliki adaptasi terhadap dua habitat yang berbeda. Jenis ikan ini lebih menyerupai amfibi daripada ikan (Garbutt dan Prudente 2006).
Ikan gelodok memiliki beragam jenis namun memiliki banyak kesamaan secara morfologi. Perbedaan jenis makanan dapat menunjukkan perbedaan jenis dari ikan gelodok. Beberapa jenis mengambil lumpur ke dalam mulut, menyimpan materi alga dan membuang sisanya. Beberapa omnivora, memakan crustacea kecil 
dan materi tumbuhan. Beberapa karnivora, memakan kepiting, insekta, siput dan bahkan beberapa ikan gelodok lainnya (Whitten et al. 2000). Ikan gelodok merupakan ikan yang hanya dapat ditemukan di lingkungan mangrove karena ketersediaan makanan di mangrove yang melimpah dan sesuai dengan kebutuhan nutrisi.

Makanan merupakan salah satu faktor yang sangat penting bagi organisme ikan. Makanan menentukan luas penyebaran suatu jenis dan dapat mengontrol besarnya suatu populasi. Organisme hidup, tumbuh dan berkembang karena energi yang berasal dari makanan. Makanan pada lambung dikelompokkan sebagai makanan utama dan makanan tambahan. Makanan suatu jenis ikan menentukan kedudukan ikan di lingkungan yaitu sebagai predator atau kompetitor (Ibrahim et al. 1871).

$$
\text { Menurut Effendi }
$$

kebiasaan makanan ikan (food habits) menyangkut kuantitas dan kualitas makanan yang dimakan oleh ikan. Selanjutnya Nikolsky(1963) mengemukakan bahwa suatu organisme dapat hidup, tumbuh dan berkembang karena adanya energi yang berasal dari makanan, sehingga Beckman (1962) menyatakan bahwa makanan merupakan faktor pengontrol penting dalam menghasilkan sejumlah ikan di suatu perairan dan kekurangan makanan merupakan faktor pembatas terhadap populasi ikan di perairan umum.

Penelitian tentang kebiasaan makanan ikan gelodok di kawasan mangrove Pantai Meras belum pernah dilakukan. Beberapa penelitian sebelumnya yang telah dilakukan mengenai kebiasaan makanan ikan gelodok seperti penelitian dari Manuel (2011), dengan hasil penelitian diperoleh jenis-jenis makanan terdiri atas Crustacea, serangga, Polychaeta dan Alga; Penelitian Udo (2002) diperoleh jenis-jenis makanan ikan gelodok terdiri dari Alga, Arachnida, Crustacea, detritus, ikan, Moluska, Chilopoda, Insekta, zat-zat makrofit, Nematoda, butiran pasir dan Fungi. Untuk itu, maka perlu dilaksanakan penelitian mengenai kebiasaan makanan ikan gelodok di kawasan mangrove desa Meras sehingga dapat diketahui variasi jenis makanan dari ikan gelodok yang diperoleh di pantai Meras.Penelitian ini bertujuan untuk mengkaji mengenai kebiasaan makanan ikan gelodok yang menyangkut jenis-jenis makanan, presentase nilai suatu jenis makanan untuk mengetahui makanan utama, tambahan dan pelengkap.

\section{METODE}

Pengambilan data dan analisis data hasil penelitian dilakukan pada bulan Maret-Juni 2013. Lokasi penelitian dilaksanakan di kawasan mangrove Pantai Meras Kecamatan Bunaken dan Laboratorium Hidrobioekologi dan Manajemen Sumberdaya Perairan Fakultas Perikanan dan IImu Kelautan Universitas Sam Ratulangi. Alat-alat yang digunakan pada saat pengambilan data di lapangan yaitu alat tulis-menulis, kertas $\mathrm{pH}$, thermometer, Salinometer, jaring, ember, Kamera digital (Samsung DV 100), plastik sampel. Alat-alat yang digunakan di laboratorium untuk pemeriksaan jenis makanan adalah cawan petri, mikroskop, pipet, gunting dan botol roll film. Bahan yang digunakan adalah sampel ikan gelodok (Periophthalmus sp.). Bahan kimia yang digunakan adalah etanol $70 \%$ dan formalin $40 \%$. Metode yang digunakan di lapangan adalah metode random sampling dan untuk mengidentifikasi jenis-jenis makanan 
ikan menggunakan mikroskop dengan pembesaran 100x.

Ikan gelodok yang dianalisis diambil dari stasiun pengambilan contoh yaitu kawasan mangrove pantai Meras. Ikan gelodok ditangkap menggunakan alat tangkap berupa jaring. Kemudian ikan yang ditangkap dimasukkan ke dalam plastik sampel yang berisi alkohol $70 \%$ dan selanjutnya dianalisis di laboratorium. Jumlah ikan gelodok digunakan untuk analisis kebiasaan makanan berjumlah 30 individu. Metode yang dipakai adalah metode frekwensi kejadian dan presentase nilai satu jenis makanan dan Indeks Bagian Terbesar (Index of Preponderance).

Setiap individu ikan gelodok dibedah, diambil lambung dan ususnya untuk pemeriksaan jenis makanannya. Makanan yang ada dalam lambung dan usus ikan tersebut dikeluarkan dan ditampung dalam cawan petri. Isi lambung dan usus dariikan gelodok diawetkan dengan formalin $40 \%$ dan dimasukkan ke dalam botol roll film. Identifikasi jenis makanan dan penentuan persentase nilai dari setiap jenis makanan dikerjakan dengan menggunakan alat bantu mikroskop cahaya. Jenis makanan yang terlihat dalam mikroskop dipotret sampai seluruh jenis makanan diambil gambarnya. Hal ini dikerjakan sampai 30 individu sampel. Hasil potret jenis makanan dari setiap individu disusun dan dinilai besaran makanannya berdasarkan jenis-jenis makanan dalam persentase.

Data frekwensi kejadian dan persentase nilai suatu jenis makanan dari 30 individu sampel ikan gelodok digunakan untuk mendapatkan Indeks Bagian Terbesar (Index of Preponderance). Indeks ini merupakan gabungan dari metode frekwensi kejadian dan metode nilai (modifikasi dari Natarajan dan Jingran, 1961) dalam Effendi (1979) dengan rumus :

$\mathrm{I}_{\mathrm{i}}=\frac{\mathrm{N}_{\mathrm{i}} \times \mathrm{F}_{\mathrm{i}}}{\sum\left(\mathrm{N}_{\mathrm{i}} \times \mathrm{F}_{\mathrm{i}}\right)} \times 100 \%$

$\mathrm{I}_{\mathrm{i}}=$ Indeks Bagian Terbesar

$\mathrm{N}_{\mathrm{i}}=$ Persentase nilai satu jenis makanan

$F_{i}=$ Persentase kejadian satu jenis makanan

$\Sigma\left(\mathrm{N}_{\mathrm{i}} \times \mathrm{F}_{\mathrm{i}}\right)=$ Jumlah $\mathrm{N}_{\mathrm{i}} \times \mathrm{F}_{\mathrm{i}}$ dari semua jenis makanan

\section{HASIL DAN PEMBAHASAN \\ Deskripsi Lokasi Penelitian}

Penelitian telah dilaksanakan di kawasan hutan mangrove sekitar Desa Meras Kecamatan Bunaken Kota Manado. Wilayah sampling terletak pada titik koordinat 1032'56.93"LU, $\quad 124^{0} 49^{\prime} 02.56 " B T$. Kawasan mangrove ini didominasi jenis bakau yaitu Avicennia sp., Sonneratia sp. dan Rhizopora sp. dengan substrat lumpur berpasir. Kadar garam (salinitas) perairan berkisar 17-18 \%o dan temperatur antara $33-35^{\circ} \mathrm{C}$, kadar $\mathrm{pH}$ air sebesar 8. Kadar salinitas yang sedang menunjukkan adanya pengaruh air tawar, sedangkan $\mathrm{pH}$ menunjukkan pengaruh air laut. Parameter di lingkungan tersebut di atas merupakan kisaran toleransi bagi kehidupan ikan gelodok di kawasan hutan mangrove Meras.

\section{Makanan dan Kebiasaan Makan}

Berdasarkan analisis terhadap isi usus dan lambung dari 30 individu ikan gelodok (Periophthalmus sp.) yang ditangkap diperoleh 5 kelompok besar makanan yaitu Crustacea terdiri dari kepiting (Scylla sp.) dan udang (Penaeus sp.), Zooplankton terdiri dari Larva kepiting (Scylla sp.), Copepoda (Euterpina sp.), Larva kerang 
(Bivalvia), dan embrio ikan, Fitoplankton terdiri dari Coscinodiscus sp., Ulothrix sp., Surirella sp., Polychaeta yaitu Lepidasthenia sp dan Hexapoda yaitu Semut (Lasius sp.). Komposisi jenis makanan ikan gelodok diperoleh berdasarkan Indeks Bagian Terbesar yang dapat dilihat pada Tabel 1, disajikan pula dalam bentuk histogram (Gambar 1).

Berdasarkan Tabel 1, nilai $F_{i}$ atau persentase kejadian satu jenis makanan menerangkan bahwa Crustacea, Zooplankton, Polychaeta dan Fitoplankton sering ditemukan dalam usus dan lambung ikan. Hal ini menunjukkan bahwa makanan ini cukup banyak tersedia di lingkungan. Kondisi ini juga menandakan bahwa tekanan pemangsaan ikan gelodok hampir menyeluruh terhadap semua makanan di lingkungan. Nilai $\mathrm{N}_{i}$ atau persentase nilai satu jenis makanan, menunjukkan bahwa makanan yang ukurannya besar dalam usus dan lambung ikan yaitu terdiri dari Crustacea, Zooplankton dan Polychaeta sedangkan yang paling sedikit ditemukan adalah Fitoplankton dan Hexapoda.

Ikan yang dianalisis isi saluran pencernaan berukuran dewasa, sehingga berdasarkan frekwensi kehadiran makanan dan persentase nilai jenis makanan dalam usus dan lambung, ikan gelodok dewasa dapat digolongkan sebagai karnivora.

Tabel 1. Perhitungan Nilai Indeks Terbesar

\begin{tabular}{|c|c|c|c|c|}
\hline No & Jenis Makanan & $\mathrm{F}_{\mathrm{i}}(\%)$ & $\mathrm{N}_{\mathrm{i}}(\%)$ & $\mathrm{I}_{\mathrm{i}}(\%)$ \\
\hline 1 & Crustacea & 83.3 & 51.6 & 54.5 \\
\hline 2 & Zooplankton & 90 & 23.2 & 26.5 \\
\hline 3 & Fitoplankton & 70 & 8.1 & 7.2 \\
\hline 4 & Polychaeta & 63.3 & 13.3 & 10.7 \\
\hline 5 & Hexapoda & 23.3 & 3.8 & 1.1 \\
\hline
\end{tabular}

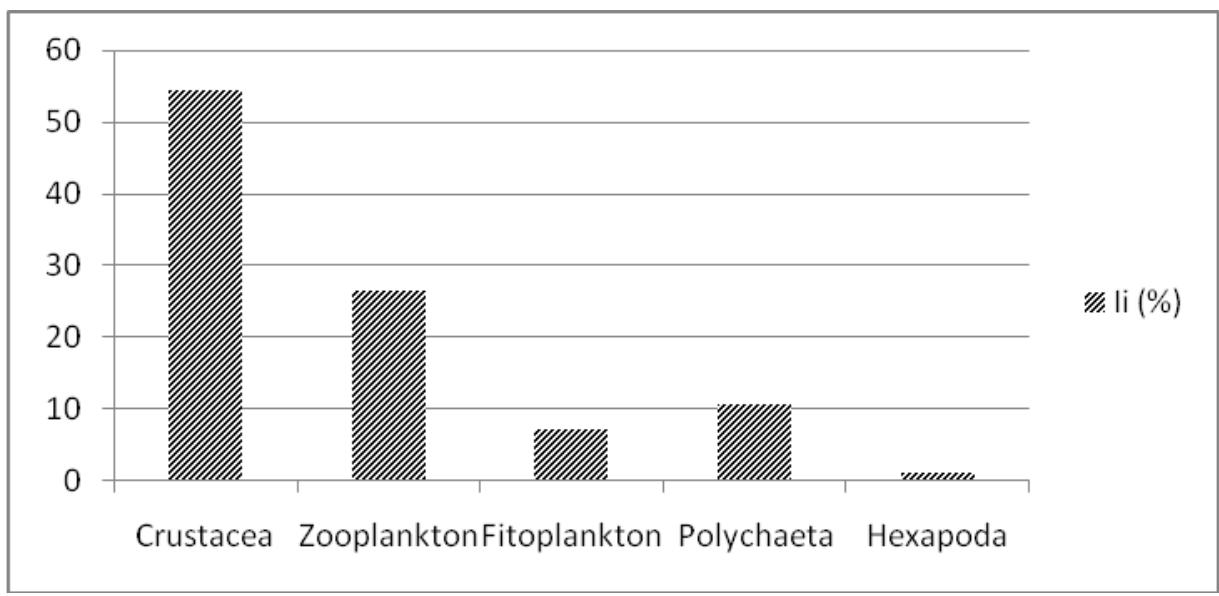

Gambar 1. Komposisi jenis makanan ikan gelodok

Hal ini sesuai dengan yang dikatakan (Barnes et al. 2005) bahwa ikan gelodok yang termasuk dalam genus
Periophthalmus adalah karnivora. Secara keseluruhan dapat dikatakan bahwa ikan gelodok selektif dalam 
memilih makanan. Fitoplankton yang termakan diduga terikut bersama jenis makanan yang utama diambil oleh ikan gelodok, sehingga perlu dikaji kembali apakah fitoplankton dicerna di usus dan lambung ikan. Penelitian tentang jenis makanan ikan gelodok yang berada di dalam rektum sejauh ini belum ada publikasinya. Hal ini akan membuktikan bahwa jenis makanan dalam rektum tidak dicerna dan bukan merupakan makanan ikan.

Menurut Effendi (1978), umumnya makanan yang pertama kali diambil oleh ikan dalam mengawali hidupnya adalah plankton yang berukuran kecil yang sesuai dengan ukuran mulut. Oleh karena dalam penelitian ikan gelodok yang diambil berukuran dewasa, maka komposisi makanan yang terdapat dalam pencernaan dapat menerangkan bahwa ikan gelodok lebih menyukai makanan hewani sebagai makanan utama ikan ini.

$\begin{array}{ccr}\text { Hasil analisis } & \text { dengan } \\ \text { menggunakan Indeks } & \text { Bagian } \\ \text { Terbesar } & \text { menyatakan } & \text { bahwa } \\ \text { makanan utama adalah } & \text { Crustacea, } \\ \text { makanan pengkap } & \text { adalah }\end{array}$ Zooplankton, Fitoplankton, Polychaeta dan makanan tambahan adalah Hexapoda. Hal ini sesuai dengan Nikolsky (1963) yang membedakan jenis makanan ikan menjadi tiga golongan menurut Indeks Bagian Terbesar (IBT), yaitu :

a) Makanan utama, jika nilai IBT > $40 \%$,

b) Makanan pelengkap, jika nilai IBT $4-40 \%$, dan

c) Makanan tambahan, jika nilai IBT $<4 \%$.

Berdasarkan frekwensi kejadian Zooplankton dan Crustacea merupakan makanan yang paling banyak ditemukan di saluran pencernaan ikan. Subfilum hexapoda merupakan jenis makanan yang paling sedikit ditemukan dibandingkan makanan utama dan pelengkap.

\section{KESIMPULAN}

Berdasarkan hasil analisis pada lambung dan usus ikan gelodok (Periophthalmus sp.) maka dapat disimpulkan bahwa jenis-jenis makanan terdiri dari Crustacea, Zooplankton, Fitoplankton, Polychaeta dan Hexapoda. Crustacea merupakan makanan utama dengan persentase sebesar 54.5\%, Zooplankton (26.5\%), Fitoplankton (7.2\%), Polychaeta (10.7\%) merupakan makanan pelengkap dan Hexapoda (1.1\%) merupakan makanan tambahan.

\section{DAFTAR PUSTAKA}

Barnes H, Ansell A, Gibson R, Barnes $M$ (2005) Oceanography and marine biology: an annual review, Volume 31. UCL Press. London

Beckman WC (1962) The Freshwater fishes of Syria and their general biology and management. FAO. Rome

Effendi MI (1979) Metoda biologi perikanan. Yayasan Dewi Sri, Bogor

(1978) Biologi perikanan (Bagian I: Studi natural history). Fakultas Perikanan Institut Pertanian. Bogor

Garbutt N, Prudente C (2006) Wild Borneo: the wildlife and scenery of Sabah, Sarawak, Brunei and Kalimantan. New Holland Publishers. London

Ibrahim A, Saleh R, Hasriani (1871) Aspek Kebiasaan Makanan Ikan Kurisi Bali (Pristipmoides multidens) yang tertangkap di Perairan Derawan dan sekitarnya. Borneo University Library (1): 1-6

Manuel F (2011) Food and feeding ecology of the Mudskipper 
Gosal dkk., Kebiasaan makanan ...49

Periopthalmus koelreuteri (PALLAS) Gobiidae at Rumuolumeni Creek, Niger Delta, Nigeria. Agric Biol J North America 2(6): 897-901

Nikolsky, GV (1963) The Ecology of Fishes. Academic Press, New York and London.

Udo M (2002) Trophic attributes of the mudskipper, Periophtalmus barbarous (Gobiidae : Oxudercinae) in the mangrove swamps of Imo River Estuary, Nigeria. J Environ Sci 14(4): 508-517

Whitten T, Damanik S, Anwar J,Hisyam N (2000) The Ecology of Sumatra. Periplus Edition. Singapura 